\title{
25. Morphology and Ontogeny of Wheat Leaf Rust (Puccinia recondita f. sp. tritici) Uredinio. spores produced on Artificial Medium*)
}

\author{
By Katsuhiko Ando and Keizo KatsuyA \\ Institute of Agriculture and Forestry, University of \\ Tsukuba, Ibaraki 305 \\ (Communicated by Naohide Hira'tsuka, M. J. A., April 13, 1981)
}

Few reports have been published on the morphology and ontogeny of spores produced in colonies of rust fungi grown on artificial media. This report describes the effect of temperature on the size of spores produced in axenic colonies of wheat leaf rust, spore ontogeny and SEM observation of the colonies and spores.

Materials and methods. Urediniospores of Puccinia recondita Rob. ex Desm. f. sp. tritici Eriks. and Henn. race 45 maintained on potted wheat seedlings (cv. Norin 16) were used. The axenic culture of the wheat leaf rust was carried out according to the method described in a previous paper ;2) urediniospore-infected wheat leaf segments were sterilized and placed on Czapek-Dox agar slants containing peptone and yeast extract. The segments were kept under four temperature conditions in darkness $(10 \pm 1,15 \pm 1,20 \pm 1$ and $25 \pm 1 \mathrm{C})$. Two to 3 months after culturing, colonies developed onto the medium were examined with the following methods. (1) For measurement of urediniospores and amphispores produced in the colonies, pieces of colonies were mounted in a drop of $0.5 \% \mathrm{KOH}$ or lactophenol on glass slides, and covered with a cover slip. One hundred urediniospores and 50 amphispores produced under each of the culture conditions (except 20 amphispores at $10 \mathrm{C}$ ) were measured under a light microscope. (2) Colonies were examined by the paraffin section method described previously. ${ }^{2)}$ (3) Pieces of colonies were fixed in $2 \%$ glutaraldehyde solution, rinsed with 2 or 3 changes of distilled water and dehydrated in a graded series of ethanol. They were immersed in a solution of 50 and $100 \%$ ethanol-amylacetate and dried with a Hitachi Critical Point Dryer. The samples were placed on a double-sided adhesive tape mounted on specimen holders, and then coated with gold with an Eiko IB-3 Ion Coater operating under high vacuum. Micrographs were obtained with a Hitachi S-430 Scanning Electron Microscope (SEM) operating at $20 \mathrm{KV}$. (4) Microtome sections were

*) Contribution no. 16, Laboratories of Plant Pathology and Mycology, Institute of Agriculture and Forestry, University of Tsukuba. 
Table I. Size of urediniospores and amphispores produced in colonies of wheat leaf rust cultured at $10,15,20$ and $25 \mathrm{C}$ in darkness

\begin{tabular}{|c|c|c|c|c|}
\hline $\begin{array}{l}\text { Culture } \\
\text { temp. }\end{array}$ & Spore & Size (um) & of spore & (mean \pm standard error) \\
\hline \multirow[b]{2}{*}{$25 \mathrm{C}$} & Urediniospore & $15.6-33.6 x$ & $12 \cdot 0-28.8$ & $(23.1 \pm 3.0 \times 20.0 \pm 2.9)$ \\
\hline & Amphispore & $19.2-28.8 x$ & $19.2-26.4$ & $(23.4 \pm 2.2 \times 21.7 \pm 1.8)$ \\
\hline \multirow{2}{*}{$20 \mathrm{C}$} & Urediniospore & $16.8-28.8 \mathrm{x}$ & $12 \cdot 0-26.4$ & $(22.4 \pm 2.2 \times 21.0 \pm 2.3)$ \\
\hline & Amphispore & $18.0-26.4 \mathrm{x}$ & $16 \cdot 5-24.0$ & $(22.4 \pm 2.0 \times 21.0 \pm 1.4)$ \\
\hline \multirow{2}{*}{$15 \mathrm{C}$} & Urediniospore & $19.2-40.8 x$ & $16.8-33.6$ & $(24.4 \pm 3.1 \times 23.0 \pm 2.3)$ \\
\hline & Amphispore & $16 \cdot 8-22.8 x$ & $14.4-21.6$ & $(19.9 \pm 1.6 \times 18.9 \pm 1.6)$ \\
\hline \multirow{2}{*}{$10 \mathrm{C}$} & Urediniospore & $18 \cdot 0-31.2 \mathrm{x}$ & $16.8-31.2$ & $(22.2 \pm 2.3 \times 21.0 \pm 1.9)$ \\
\hline & Amphispore & $18.0-26.4 \mathrm{x}$ & $16.8-25.2$ & $(21.1 \pm 2.1 \times 20.5 \pm 1.9)$ \\
\hline $20 \mathrm{C}$ & Urediniospore* & $19.2-26.4 \times$ & $18 \cdot 0-25.2$ & $(22.8 \pm 1.9 \times 21.3 \pm 1.6)$ \\
\hline
\end{tabular}

mounted on specimen holders, immersed in a solution of 50 and $100 \%$ ethanol-amylacetate and dried by the critical point method. The samples were coated with gold and photographed under the SEM.

Results and discussion. Two different colonies developed from aseptic urediniospore-infected wheat leaf segments cultured on artificial medium; one was a "sporulation colony" grown at 15, 20 and $25 \mathrm{C}$ in darkness, the other was a "reproductive colony" (manuscript in preparation) grown at 10 and $15 \mathrm{C}$ in darkness. Many urediniospores were produced in both colonies cultured under different temperature conditions within two months after culturing. Range of the sizes of urediniospores produced in the colonies grown under different temperature conditions was wider than that on wheat seedlings, but the means of the spore sizes were similar to those on the host (Table I). There was no significant difference among sizes of spores produced under the 4 culture conditions. Amphispores, which were thick-walled, were produced in the "sporulation colonies" and the "reproductive colonies", though spores were not observed in the rust uredinia on wheat seedlings growing in a cabinet at $20 \mathrm{C}$. Amphispore size varied, and frequency of the production of amphispores in colonies was related with the temperature of the culture; as the temperature increased amphispore production also increased, though the size was not affected by the temperature.

SEM observation of the "sporulation colony" revealed that uredinia produced on the colony were hemispheric (Fig. 1) and covered with an unknown material (Fig. 2). The "reproductive colony" was also covered with the same unknown material. Urediniospores covered with a film-like material were sometimes observed in both 
the colonies (Fig. 3). Bose and Shaw ${ }^{3)}$ observing urediniospores grown in vitro which were covered with a layer of unknown material suggested that the inability of the urediniospores to infect intact leaves was related to the presence of the unknown material. The filmlike material observed in the present study may be the same as the unknown material described by Bose and Shaw. ${ }^{3)}$ If so, the material coating urediniospores did not prevent them from infecting intact leaves, because wheat seedlings could become infected with urediniospores produced in the "reproductive colonies" ( manuscript in preparation). The film-like material covering the urediniospores may be considered as the primary wall described by Amerson and Van Dyke. ${ }^{1)}$ Generally, in urediniospores produced on host leaves the primary wall disappears as urediniospores become mature, but in the colonies it has been suggested that the wall does not readily disappear from the urediniospore.

SEM observations of urediniospores in the "reproductive colonies" and the "sporulation colonies" revealed the existence of urediniospores without spines (Fig. 4), with developing spine (Fig. 5), and some in which polygonal ridges could be found (Fig. 6). These were thought to correspond to the development process of spines on urediniospores, which was similar to that observed by Amerson and Van Dyke ${ }^{1)}$ on host leaves infected with Puccinia sparganioides.

SEM observation of microtome sections of the "sporulation colonies" showed scattered germ-pores on the wavy inner wall of the urediniospores (Fig. 7). Cytoplasm of the urediniospores germinating in colonies migrated to the germ-tubes (Fig. 8). Urediniospores contained one to two spherical bodies $(2.9-3.3 \mu \mathrm{m}$ in diam) which may be considered as nuclei because of their number and size (Fig. 9).

"Reproductive colonies" were useful for the study of urediniospore ontogeny. A sporogenous cell was differentiated at the tip of the vegetative mycelium and the cell bore one to five stalk cells, leading to the formation of echinulate urediniospores on the stalk cells (Fig. 10). Urediniospores were pedicellate in general, but occasionally they originated directly from sporogenous cells (Figs. 11 and 12). As shown in Fig. 13 which is a scanning electron microphotograph of a microtome section of a "reproductive colony", pedicellate and sessile urediniospores were also produced from one sporogenous cell. In axenic cultures of Puccinia graminis f. sp. tritici, Bose and Shaw ${ }^{3)}$ and Rajendren $\left.{ }^{6}\right)$ reported that urediniospores were produced on stalk cells (pedicellate). Since Moss ${ }^{4)}$ described the process of urediniospore development on host plants, it has been accepted that urediniospores were formed singly on pedicels derived from sporogenous cells. McGinnis, ${ }^{5)}$ however, reported from observations on urediniospore 


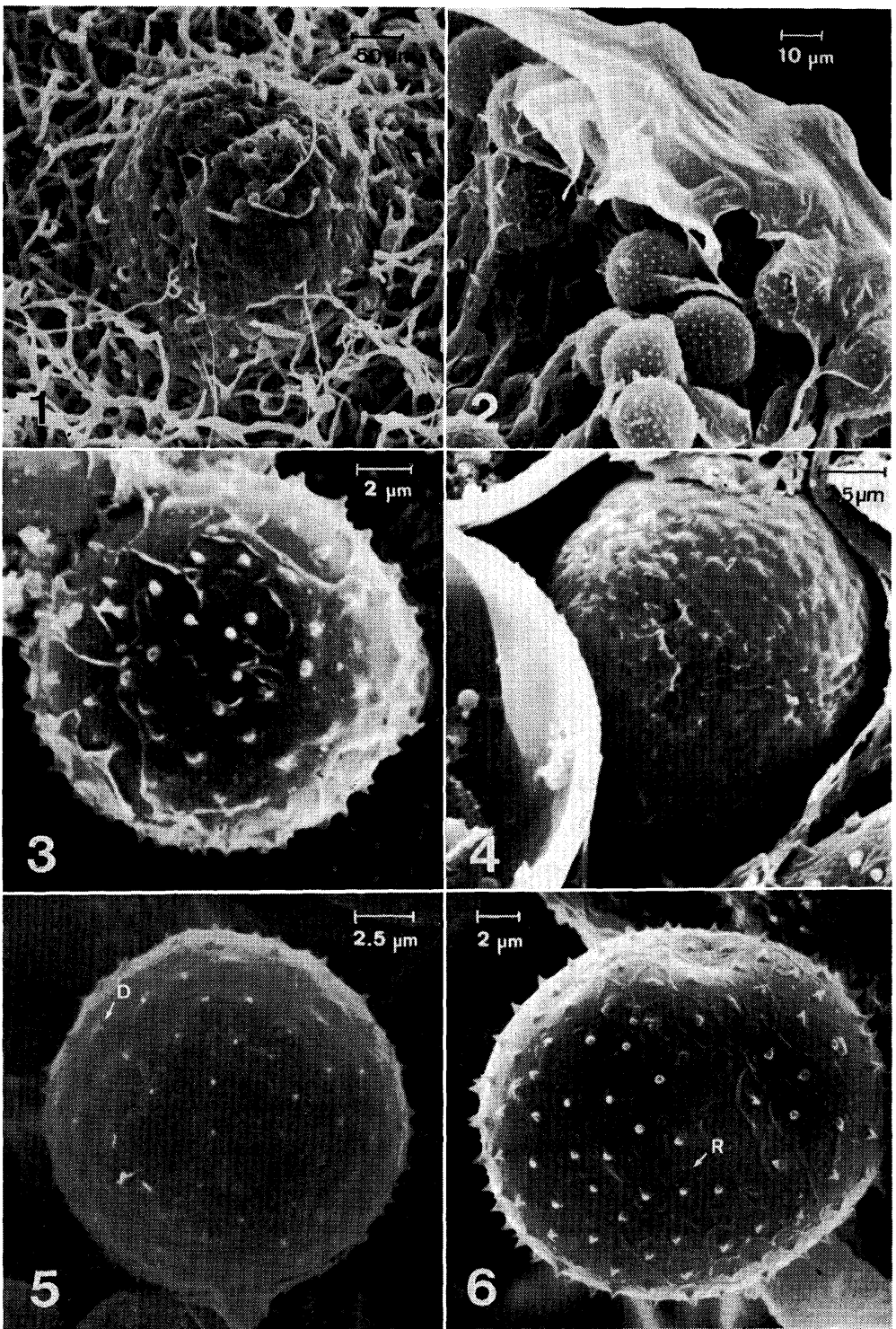

Figs. 1-6. 1, 2: Uredinium, which was covered with an unknown material, produced on "sporulation colonies". 3-6: Urediniospores produced in colonies. 3: Spore covered with a film-like material. 4: Young spore lacking spine development on the surface. 5: Spore showing small circular depressions (D) around spines. 6: Spore showing ridges (R) and spines.

ontogeny of Hyalopsora polypodii on fern that urediniospores were usually pedicellate but occasionally sessile, which is in agreement with the present observation in vitro. Sporogenous cells were produced from the terminal cells of vegetative mycelia, and sometimes from 


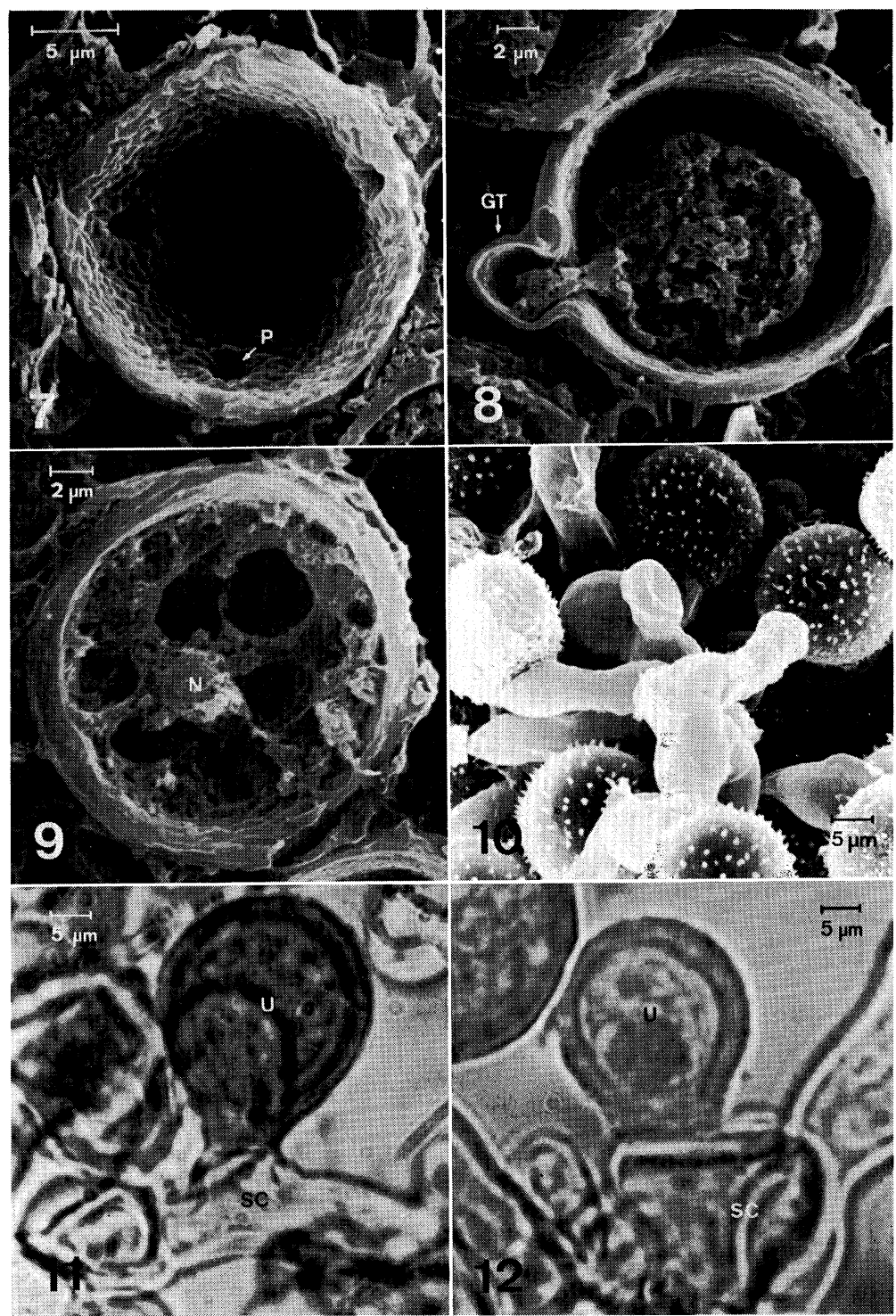

Fig. 7-12. 7: The wavy inner wall and germ-pores of an urediniospore. 8: Urediniospore elongating the germ-tube (GT). 9: A spherical body (N), considered as a nucleus, in urediniospore cytoplasm. 10: Pedicellate urediniospores produced in "reproductive colony". 11, 12: Sessile urediniospores (U) produced directly from the sporogenous cells (SC).

sporogenous cells. Consequently, several sporogenous cells were connected with each other (Fig. 14). In this case, the urediniospores developed as sympodioconidia in opposition with the ontogeny of the Fungi Imperfecti. 

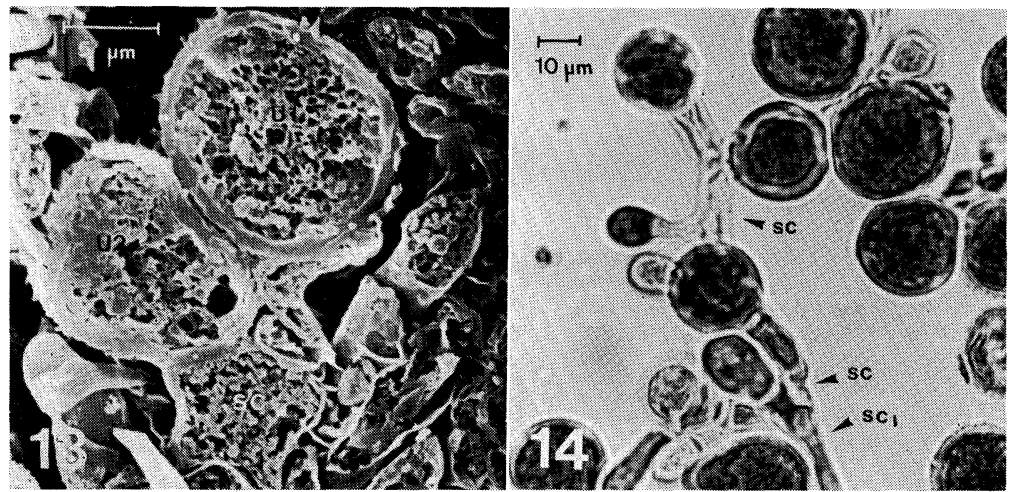

Figs. 13, 14. 13: Pedicellate (U1) and sessile (U2) urediniospores produced from a sporogenous cell. 14: Successive urediniospore production; the first sporogenous cell (SC1) is producing sporogenous cells with pedicellate spores.

As shown in this experiment the presence of saprophytic colonies enabled to study the detailed characteristics of wheat leaf rust obtained after removing the rust fungus from the host tissue which had made it difficult to observe rust characteristics such as spore ontogeny. The observation of the characteristics of rust fungi grown on media may improve some concepts on the taxonomy of rust fungi.

Acknowledgement. The authors wish to offer their thanks to Dr. Naohide Hiratsuka, Professor Emeritus of Tokyo University of Education, for his encouragement and introduction to Proceedings of the Japan Academy.

\section{References}

1) Amerson, H. V., and Van Dyke, C. G.: Exp. Mycol., 2, 41-50 (1978).

2) Ando, K. et al.: Ann. Phytopath. Soc. Japan, 45, 660-667 (1979).

3) Bose, A., and Shaw, M.: Can. J. Bot., 49, 1961-1964 (1971).

4) Moss, E. H.: Ann. Bot., 15, 813-847 (1926).

5) McGinnis, M. R.: Mycologia, 69, 509-513 (1977).

6) Rajendren, R. B.: ibid., 64, 591-598 (1972). 